\title{
Refractive Errors and Amblyopia in Scholar's Population in Togo
}

\author{
Hillah Amah Biova Kossi* and Mar Argudo \\ Department of Optometrist, School of Advanced Education Research and Accreditation (SAERA), Spain
}

Submission: January 09, 2019; Published: February 12, 2019

*Corresponding author: Hillah Amah Biova Kossi, Optometrist, School of Advanced Education Research and Accreditation (SAERA), Togo

\begin{abstract}
Background: Refractive defects were identified as one immediate priority within the framework of VISION20/20.Uncorrected refractive defects are responsible for academic failure and several cases of amblyopia.

Objective: The basic aim of this study was to assess the status of refractive errors in school population, and their relation with amblyopia.

Method: The study was done on 8715 students aged 11 years to 16years, selected randomly from eight secondary government schools.

Result: Refractive errors were found in 226 (2.6\%) children out of which 33 (14.6\%) suffer from amblyopia. Astigmatism was the refractive error found more frequently (77\%), followed by myopia (11\%) and hyperopia (4.5\%).
\end{abstract}

Conclusion: Ametropias are very present in the school population and it is certain that they influence enormously the school life of children. Ametropias are also important causes of amblyopia, and low vision.

Keywords: Blindness; Ametropia; Refractive anomalies; Cephalgias; Tiredness

\section{Introduction}

In order to appreciably reduce the problem of blindness in the world, WHO as well as a broad coalition of international organizations, launched on February 16th, 1999 in Geneva a baptized world initiative "VISION 20/20: right to the sight". The objective of this new initiative is to eliminate avoidable blindness by 2020 . Refractive defects were identified as one immediate priority within the framework of VISION 20/20. Ametropia is represented by all the situations where the optical system of the eye does not make it possible to focus the image of an object on the retina (Batterbury \& Bowling, 2005). Thus, refractive anomalies have an immediate effect on the perception of objects or images and can also start several issues: cephalgias, tiredness, and pain.

A report of WHO in 1999 had estimated that the overall of refractive disorders in children lay between 2\% and 10\% 1999. With modernization, the invasion and the development of the digital screens, the statistics change continuously. One even currently speaks about an epidemic of myopia since the figures of this visual disorder are alarming [1]. Recent meta-analyses have suggested that nearly half of the world's population may be myopic by 2050 , with as much as $10 \%$ highly myopic [2]. Uncorrected refractive defects are also responsible for several cases of amblyopia. This disorder seems to assign 2 to $5 \%$ of the population according to Flom \& Neumaier [3]. Amblyopia is a cortical disorder: the part of the brain which processes the data coming from an eye does not function in an optimal way. If this visual problem is not dealt with in time, that is likely to cause the vision loss. Locating amblyopia as soon as possible in children allows a more effective treatment as Stewart et al. [4] advise.

In Togo, the real prevalence of the refractive error and amblyopia is unknown. However, a regional study carried out in school in 2011 revealed that $6.5 \%$ of the pupils had an ametropia with a vision of the better eye lower than 7/10 (Togolese Red Cross, 2015). One can thus deduce from it, that with a national population of almost seven million inhabitants of which half of them is in school age, Togo would count about two hundred thousand $(200,000)$ people of school age with an ametropia with visual acuity lower than $7 / 10$ of the best eye.

Uncorrected ametropia can have a negative impact on the school output. Indeed, these children have a possible hazard of loss of education and thus an impossibility of finding decent employment. It results a situation from it being able to generate a poor quality of life and a fall of individual and social productivity. It is then, crucial to fight against refractive error in the population especially in young people or scholars. 


\section{Objectives}

In this study, we propose to analyze, thanks to the data collected by the project "optical caravan", the prevalence of refractive defects, and their impact on vision in Togo. The first objective consists in classifying and measuring the frequency of the three main refractive defects which are myopia, hyperopia and astigmatism; these data will allow a better estimate of ametropia in the population and will be used as a basis to effectively follow the statistics of refractive errors in the population.

The second objective will be examining the cases of refractive amblyopia. Currently, we do not have of any data on the frequency of amblyopia in our population whereas it would be responsible of several cases of low vision and blindness. The third objective is related to evaluate the impact of the project and bring out the requirement of medical glasses, equipment and techniques in order improve the projects which aim at the correction of ametropia.

\section{Materials and Methods}

\section{Scope of the study}

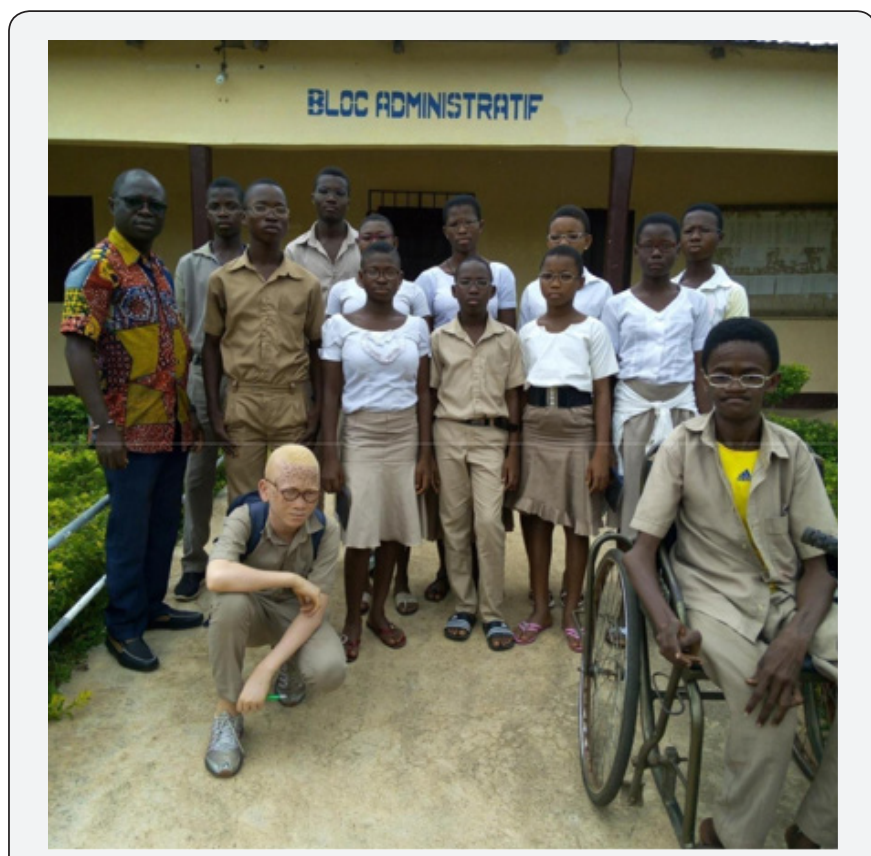

Figure1: Some students with their new spectacles.

Togo, officially the Togolese Republic, is a country in West Africa bordered by Ghana to the west, Benin to the east and Burkina Faso to the north. It extends south to the Gulf of Guinea, where its capital Lomé is located. Togo covers 57,000 square kilometers, making it one of the smallest countries in Africa, with a population of approximately 7.6 million. Togo is subdivided in five regions and thirty-nine prefectures.

The national program of fight against blindness is a state structure in charge of ocular health of the population. The national program of fight against blindness, with the assistance of the NGO Planet Vision, has to initiate since 2016 the project "optical caravan" which consists of detecting refractive errors among students and then, offering a pair of adapted glasses to correct the defect (Figure 1). This project thus made it possible to gather important information about ametropia in students population.

Table 1: Schools, Location and Date of the Screening.

\begin{tabular}{|c|c|c|}
\hline School & Prefecture & Date \\
\hline Ceg Tsevie Ville & Zio & October $25^{\text {th }}$ to $27^{\text {th }}, 2017$ \\
\hline Ceg Notse Ville & Haho & December $13^{\text {th }}$ to $15^{\text {th }}, 2017$ \\
\hline Ceg Adeta I & Adeta & March $19^{\text {th }}$ to $21^{\text {st }}, 2018$ \\
\hline Ceg Agou Gare & Agou & March $22^{\text {nd }}$ to $24^{\text {th }}, 2018$ \\
\hline Ceg Sagbado & Golfe & April $11^{\text {th }}$ to $13^{\text {th }}, 2018$ \\
\hline Geg Tabligbo & Vo & May $2^{\text {nd }}$ to $4^{\text {th }}, 2018$ \\
\hline Ceg Aklakou & Lacs & May $30^{\text {th }}, 2017$ to June $1^{\text {st }}, 2018$ \\
\hline Ceg Zebevi & Lacs & June $6^{\text {th }}$ to $8^{\text {th }}, 2018$ \\
\hline
\end{tabular}

The educational system in Togo is organized in three sections: primary school up to sixth grade, secondary school first cycle which has four grades, and secondary school second cycle with three grades. Generally, children begin school at six years old. The targets of "Optical caravan" are pupils of the secondary school first cycle between the ages of 12 to 16 years old (Table 1).

This is a transversal study which takes into account eight (8) secondary schools of the public sector. These schools are distributed in seven (7) prefectures of the country. The study unfolded over a period of one year (May 2017 to July 2018).

\section{Criteria of the study}

Inclusive criteria: All the students present, who readily agreed to be examined

Non-inclusive criteria: Students who refused the examination and those which were absent at the time of our passage. Pupils with untreated pathology that affects refraction and VA. Criteria of correction of refractive defects: pupils who have a vision with the better eye lower than $8 / 10$.

\section{Equipment and method}

For the implementation of screenings, we had the following human resources:

\section{Technical personnel}

a) Ophthalmologist: He is the chief of the mission. He will make the ophthalmologic examination of the children whose vision (VA) is lower than 8/10.

b) Ophthalmology technicians and optometrists: They will perform the VA and refractive examinations which the ophthalmologist will entrust to them. 
c) Opticians: They are in charge of making the prescribed medical glasses.

\section{Administrative staff}

a) Secretary: It will be in charge of recording and managing the student's files.

b) Logistician: He will be in charge of the organization of the activities.

c) Drivers: He will take care of the transport of equipment and staff.

In order to perform our study, we used the following equipment

\section{a) Visual acuity scale}

It is an eye chart that can be used to measure visual acuity. Illuminated Snellen E chart is used at 5 meters during screenings. It permits rapid determination of the VA, and it is very easy to use when we deal with numerous people. VA is recorded as a fraction corresponding to each line of the scale used. VA is performed eye per eye and the mark is seized on the investigation card (Figure 3). Important parameters that can affect VA are considered. To consider a mark of VA, pupils must "read" at least half of all the symbols on a line. The environment of the room has to be clear enough to validate each measure. E chart is easy enough for secondary pupils so that, effects related to experience and intelligence are reduced when making the measurements. Attention and fatigue have also been controlled, as we have three (3) or more technicians who make VA tests simultaneously.

\section{b) Trial frame}

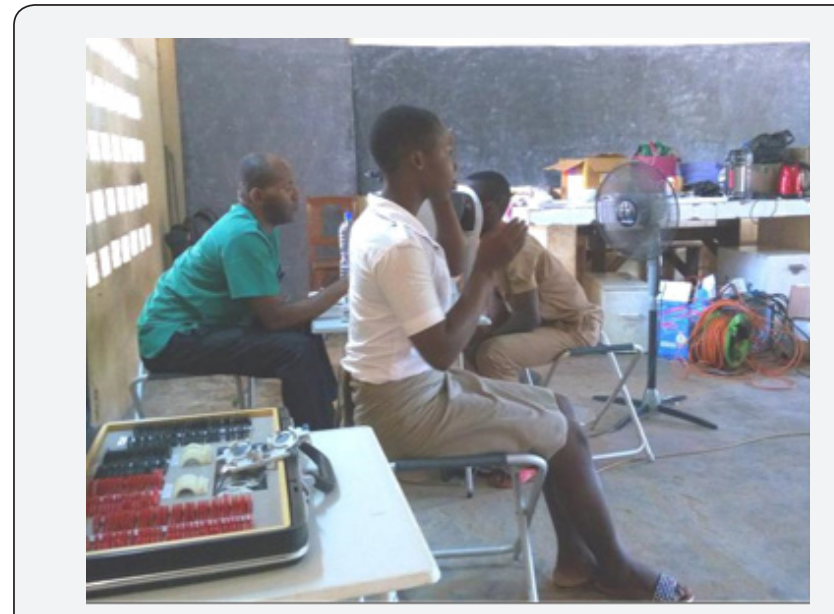

Figure 2: Performing VA and autorefractometry. Trial case lens and trial frame.

Trial frame refraction is made in all the cases (Figure 2 \& 5). Trial frame refraction is good for everyone (children, people with disabilities, people with low vision, illiterate people, those speaking a different language, elderly, high prescriptions). In order to use it properly, the trial frame is adjusted for vertex and inter-papillary distance and it adjusted to be straight on people's face.

\section{c) Slit lamp examination}

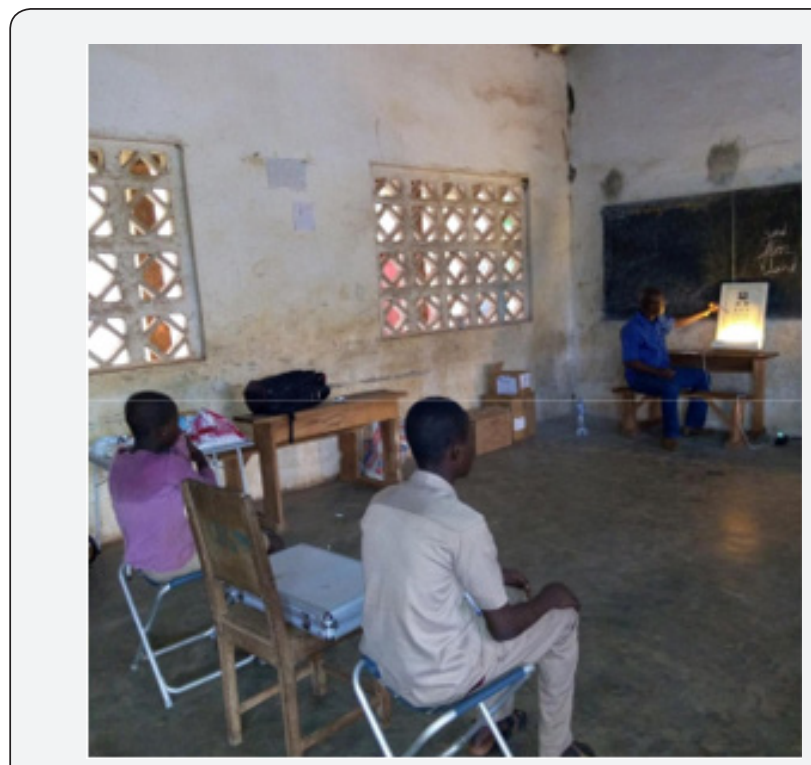

Figure 3: Performing VA at $5 \mathrm{~m}$ with Snellen E chart illuminated.

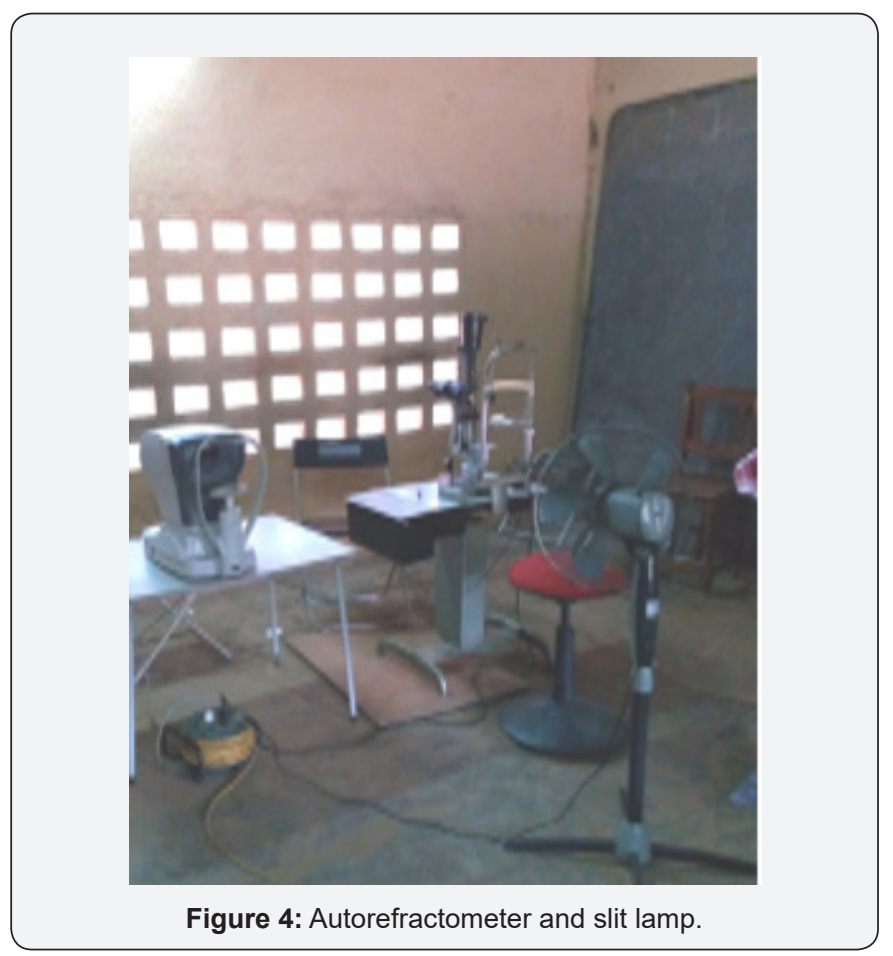

Some conditions can alter the good functioning of the eyes; and then alter the VA and refraction. The slit lamp is very important in full examination process. It facilitates observation of ocular adnexa, monitoring signs and symptoms of anterior segment conditions and investigating the posterior segment. Pupils with some pathological conditions which need medical attention have been removed from the study (Figure 4). 


\section{d) Direct ophthalmoscopy}

The ophthalmoscope allows seeing inside the eye. It is done as part of eye examination to detect posterior segment pathologies (retina, optic disc, and vitreous humour), which can affect or alter VA (Figure 5).

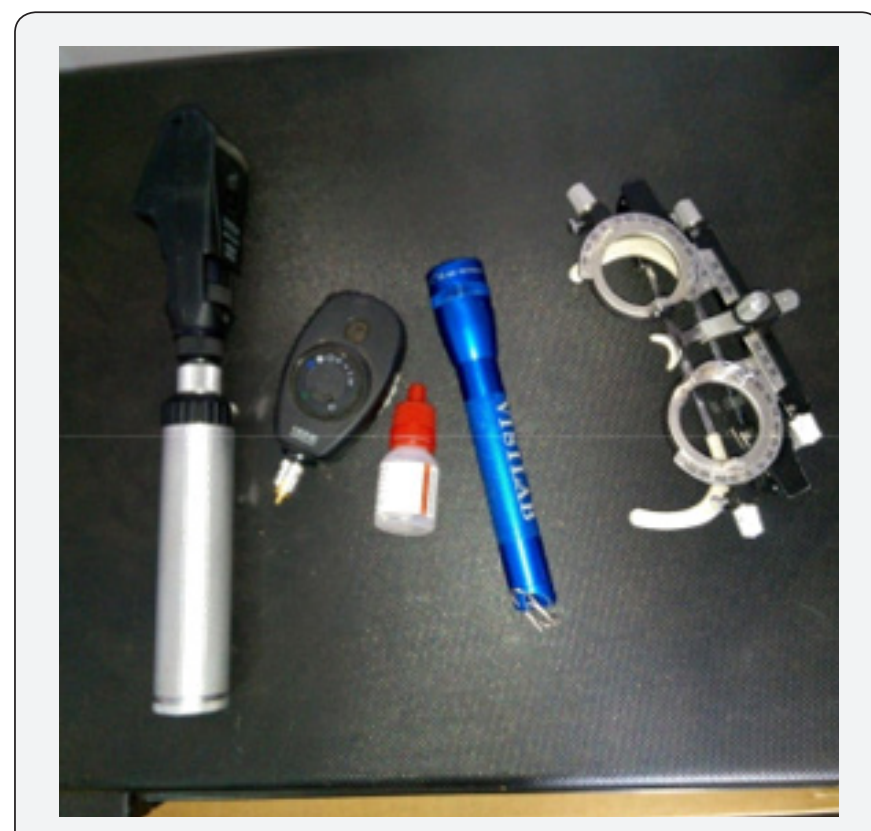

Figure 5: Retinoscope and ophthalmoscope Heine beta 200, Trial frame. Flashlight. Cycloplegic drug.

e) Retinoscopy

Retinoscopy, also called skiascopy is a technique to objectively determine the refractive error of the eye and the need for glasses. It used when they suspect that auto refractor measure is not reliable (Figure 5).

\section{f) Flashlight}

A very simple item, but useful to inspect the appendices and anterior segment of the eye (Figure 5).

\section{g) Autorefractometry}

AUTOREFRACTOR NIDEK AR 220 is used during students' screenings. It is known as very accurate; although in some cases accommodation affects the result. If a case like this is suspected, accommodation is controlled by fogging technique or cycloplegia when performing refraction (Figure $2 \& 4$ ).

\section{h) Cycloplegic eye drops}

Cycloplegic is very useful in children's refraction. It permits to relax accommodation and so obtain more accurate refraction by autorefractometry or retinoscopy (Figure 5). As we deal with children in school, we have to manage a lot their accommodation, because they use it all day to read and work at school. During the screening, accommodative spasm is found in many pupils: autorefractometry gives high myopia (over 6D), but in subjective refraction these numbers are rejected, and by efforts they manage to read up to $7 / 10$ of VA (that is normally impossible for a high myopia). In these cases, cycloplegiais mandatory. It consists of inserting eye drops of Cyclopentolate 1\% three times at 10 -minute intervals. After 40 minutes retinoscopy or autorefractometry is repeated and it frequently occurs that children have hyperopia.

\section{i) Card of investigation}

This card bears all the information concerning a pupil: name and first name, age, sex, religion, class, telephone number (own or parents), visual acuity, autorefractometry measure, refraction, eye examination data, diagnosis and treatment. From this investigation cards we gather information about ametropia, visual acuity and amblyopia (Figure 6).

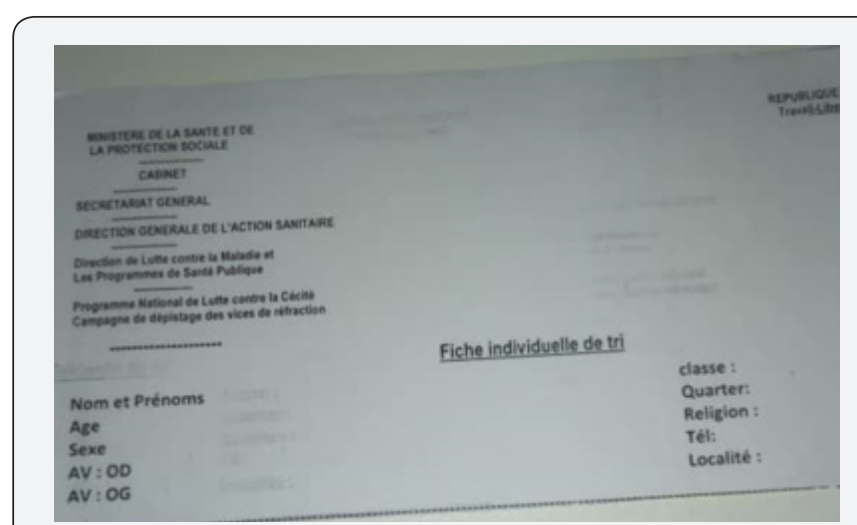

Figure 6: Investigation card which records visual acuity and personal data.

\section{Procedure}

a) Make the examination of adnexa and anterior segment of the eye with the flashlight.

b) Put the trial glasses to the pupil and hide the left eye.

c) Ask the pupil to keep both eyes opened during the test.

d) Begin with the line of VA 1/10 and then higher values were evaluated.

e) Ask the pupil for what he sees and what he can read.

f) Then measure the VA of each eye.

g) Register the data on the investigation card of survey.

h) If far VA is lower than $8 / 10$, the pupil will be referred for autorefractometry.

i) Try refraction if there is ametropia.

j) Other eye examinations are performed if necessary: eye fundus, slit lamp, etc. 
Classification used in this study. Refractive errors are classified as follows:

\section{a) Myopia}

It is the difficulty in seeing distant objects clearly; image of object in infinite is focused in front of the retina.

\section{b) Hyperopia}

In hyperopia, the optical image of an object placed at infinite is focused in rear of the retina when accommodation is relaxed. So, accommodation is used to see from far distances, and even more in order to see well a close object.

\section{c) Astigmatism}

Astigmatism is a common vision problem caused by an error in the shape of the cornea. With astigmatism, the lens of the eye or the cornea, which is the front surface of the eye, has not the same curve in all meridians. This can change the way light passes, or refracts to the retina, and two perpendicular focal images are formed in regular astigmatism.

In this study, astigmatism is those regular ones with a cylinder value of 0.75 diopters or more. Astigmatism is also categorized in:
a) $\operatorname{Direct}\left(0-30^{\circ}\right),\left(180^{\circ}-150^{\circ}\right)$
b) Inverse $\left(60^{\circ}-120^{\circ}\right),\left(240^{\circ}-300^{\circ}\right)$
c) Oblique $\left(30^{\circ}-60^{\circ}\right),\left(120^{\circ}-150^{\circ}\right)$

Myopic, hyperopic and mixed Ametropia is also classified by degree:

a) Low myopia (0.5 to 3D), Medium myopia (3.25 to $6 \mathrm{D}$ ), High myopia (6.25 D or more)

b) Low hyperopia (0.25 to 3D), Medium hyperopia (3.25 to 5D), High hyperopia (5 D or more)

c) Low astigmatism (0.50 to 1.75$)$ and high astigmatism (2.00 or more)

We call amblyopia difference in two lines between the VA of both eyes; VA with the best correction doesn't increase with pin hole, and there is not any pathology which can explain the visual loss.

Table 7: Refractive error that cause amblyopia.

\begin{tabular}{|c|c|c|c|c|c|c|}
\hline Ametropia and amblyopia & \multicolumn{3}{|c|}{ Bilateral amblyopia } & \multicolumn{3}{c|}{ Unilateral amblyopia } \\
\hline & $\mathrm{VA}<=3 / 10$ & $\mathrm{VA}<=5 / 10$ & $\mathrm{VA}<8 / 10$ & $\mathrm{VA}<=3 / 10$ & $\mathrm{VA}<=5 / 10$ & $\mathrm{VA}<8 / 10$ \\
\hline High astigmatism & 2 & 3 & 18 & & & \\
\hline High myopia & 2 & 1 & & & \\
\hline High hyperopia & & & & 1 & \\
\hline Hyperopia inferior to 2.5D & & & 2 & & & \\
\hline Myopia of 5D & & & 1 & & \\
\hline
\end{tabular}

\section{Data analysis}

Data were seized in tables and analyzed in the software Excel 2010. The dynamic cross table, the functions of sorting of this software made it possible to emphasize the most important information for our study. We have to count manually some characteristics. Calculator is used also to do some calculation and determine percentage. Word tables are used to present the results of analysis.

\section{Results}

Table 2: Prevalence of refractive error.

\begin{tabular}{|c|c|c|}
\hline & Number & $\begin{array}{c}\text { Percentage } \\
\text { Rate }\end{array}$ \\
\hline Children with VA $<8 / 10$ & 226 & $2.59 \%$ \\
\hline VA $>=8 / 10$ & 8489 & $97.4 \%$ \\
\hline Total & 8715 & $100 \%$ \\
\hline
\end{tabular}

Table 3: Refractive status of subjects.

\begin{tabular}{|c|c|c|}
\hline Refractive error status & Right Eye & Left Eye \\
\hline Astigmatism & $177(78.32 \%)$ & $174(76.99 \%)$ \\
\hline Myopia & $29(12.83 \%)$ & $22(9.73 \%)$ \\
\hline Hyperopia & $10(4.42 \%)$ & $12(5.31 \%)$ \\
\hline
\end{tabular}

Table 4: Classification of astigmatism by axis.

\begin{tabular}{|c|c|c|c|}
\hline $\begin{array}{c}\text { Types of } \\
\text { Astigmatism }\end{array}$ & Right Eye & \multicolumn{2}{|c|}{ Left Eye } \\
\hline Direct & $96(54,23 \%)$ & 97 & $(55.75 \%)$ \\
\hline Indirect & $68(38.41 \%)$ & 61 & $(35 \%)$ \\
\hline Oblique & $13(7.34 \%)$ & 16 & $(9.2 \%)$ \\
\hline
\end{tabular}

Table 5: High grade ametropia.

\begin{tabular}{|c|c|c|}
\hline High Refractive Error & Right Eye & Left Eye \\
\hline $\begin{array}{c}\text { High astigmatism (2D or } \\
\text { more) }\end{array}$ & $55(31.1 \%)$ & $51(29.31 \%)$ \\
\hline High myopia (6D or more) & $3(10.34 \%)$ & $2(9.1 \%)$ \\
\hline $\begin{array}{c}\text { High hyperopia (5D or } \\
\text { more) }\end{array}$ & 0 & 0 \\
\hline
\end{tabular}

Table 6: Refractive amblyopia and visual acuity loss.

\begin{tabular}{|c|c|c|}
\hline $\begin{array}{c}\text { Refractive Amblyopia } \\
\text { Cases }\end{array}$ & $\begin{array}{c}\text { Bilateral } \\
\text { Amblyopia }\end{array}$ & $\begin{array}{c}\text { Unilateral } \\
\text { Amblyopia }\end{array}$ \\
\hline severe $(\mathrm{VA}<=3 / 10)$ & $3(9 \%)$ & $1(3 \%)$ \\
\hline Moderate $(\mathrm{VA}<=5 / 10)$ & $5(15.15 \%)$ & 0 \\
\hline Low $\mathrm{VA}<8 / 10$ & $21(63.63 \%)$ & $3(9 \%)$ \\
\hline
\end{tabular}


The screenings permit to control 8715 pupils in secondary school. 226 pupils had ametropia with VA in both eyes inferior to $8 / 10$. The prevalence of refractive errors is about $2.6 \%$ (Table 2 ). Astigmatism was the refractive error found more frequently (average of $77 \%$ ), followed by myopia (11\%) and hyperopia $(4.5 \%)$ (Table 3). Direct or with the rule astigmatism is the present in majority with 55\%, followed by indirect (against the rule) and oblique astigmatism, 38\%; 8\% (Table 4). High refractive error is found in astigmatism (30\% of them) and myopia (9.5\%)(Table 5). 33 cases of refractive amblyopia were found. This represents a prevalence of $0.38 \%$. Low and bilateral amblyopia is $64 \%$ of amblyopia cases. Severe amblyopia is seen in 3 children(Table 6). Most of the time, astigmatism of 2D or more is responsible of refractive amblyopia (26 of the 33 cases found). It is worth to notice that moderate hyperopia is also an amblyogenic factor (Table 7).

\section{Discussion}

A study done on visual impairment in school children in southern India by Kalikivayi et al. [5] in 1990 reported prevalence rate of myopia to be $8.6 \%$; hyperopia $22.6 \%$; astigmatism $10.3 \%$. So, hyperopia seems to be the most frequent found in children. But in this study proportions are different. The great proportion of astigmatism is explained by the fact that accurate methods are used to refract pupils: Retinoscopy and autorefractometry. Often many practitioners don't correct astigmatism if they consider VA is good enough with the sphere; but we know well that even 0.25 of astigmatism can change the vision of the patient. In this study, even astigmatism of $0.5 \mathrm{D}$ is corrected because we know that these refractive errors are often causes of symptoms such as headaches, eye pain, visual fatigue; which can influence the school performance. Another factor which could influence the statistics is the refractive errors of those who were not included in the study. Among them there could be no negligible quantity of hyperope and myope. So, we have to precise that these results have to be considered together with the criteria of the study.

Garcia et al. (2005) in their study about the prevalence of refractive errors in students in North-eastern Brazil showed that hyperopia was the most common with $71 \%$, followed by astigmatism (34\%) and myopia (13.3\%). The resultant on the studies of prevalence of ametropia vary in various studies, because their criteria are often not the same, but it is necessary to indicate that certain refractive errors can be characteristic of certain ethnic groups or regions. There is also difference in rural and cities populations [6].

High ametropia is an important risk factor for amblyopia. The study showed us that they are responsible for $88 \%$ of the cases of refractive amblyopia. High astigmatism is present for the greater part; but in most cases it causes low amblyopia. High hyperopia is a cause of severe amblyopia even if it is rarer. It is important to note that even uncorrected moderate hyperopia causes amblyopia.

Table 8: Reported prevalence of amblyopia in various study.

\begin{tabular}{|c|c|}
\hline $\begin{array}{c}\text { Preschool } \\
\text { and School-age Children }\end{array}$ & $\begin{array}{c}\text { Percentage Reported } \\
\text { with Amblyopia }\end{array}$ \\
\hline Friedman et al. & 0.5 \\
\hline Russell et al. & 1.3 \\
\hline Da Cunha and Jenkins & 1.7 \\
\hline Flom \& Neumaier [3] & 1.8 \\
\hline McNeil & 2.7 \\
\hline Frandsen & 3.1 \\
\hline Vereecken et al. & 3.5 \\
\hline Thompson et al. [16] & 3.0 \\
\hline ALSPAC: early screening & 1.1 \\
\hline ALSPAC: late screening & 2.0 \\
\hline Eibschitz-Tsimhoni et al.: early screening & 1.0 \\
\hline Eibschitz-Tsimhoni et al.: late screening & 2.6 \\
\hline
\end{tabular}

In this study, the prevalence of amblyopia is about $0.4 \%$, a figure which is not very far from those published in other studies. In fact, several studies which were made on prevalence of the amblyopia gave the following results [7] (Table 8). The use of Cycloplegic in screenings is very important, since often many cases of hyperopia are not reported. Indeed, many children who reach 10/10 visual acuity could have low and moderate hyperopia. As they are young, this hyperopia is not manifest in decreasing VA, but instead it causes nonspecific symptoms such as fatigue, pain in or around the eyes or episodic blurred vision [8-10].

\section{Conclusion}

Ametropias are very present in the school population in Togo, and it is certain that they influence enormously the school life of the children and by consequence the whole society [1115]. Astigmatisms affect a lot of people, thus in the projects which fight against ametropia, it is necessary to plan a large number of cylindrical glasses. Ametropias are also important causes of amblyopia, and low vision. Amblyopia is a real social plague whose origins can be multiple. The only remedy is early screening.

A school screening program is an effective way to detect the causes of visual impairment in school children. It is worthy to use for these screenings an objective and accurate technique that reflects the real refractive status of children [16-18]. Though we have to be careful in extrapolating the results of this study to the entire population of school children in Togo, but these data validate the need for vision screening of school children. School screening programmes should be mandatory by the government health authorities. 


\section{References}

1. Pascolini D, Mariotti SP (2010) Global estimates of visual impairment. Brazilian journal of Ophthalmology 96(5): 614-618.

2. Holden, Fricke TR, Wilson DA, Jong M, Naidoo KS, et al. (2016) Global prevalence of myopia and high myopia and temporal trends from 2000 through 2050. Ophthalmology 123(5): 1036-1042.

3. Flom M, Neumaier R (1966) Prevalence of amblyopia. Public Health Report 81(4): 329-341.

4. Stewart CE, Moseley MJ, Fielder AR, DA Stephens (2004) Refractive adaptation in amblyopia: quantification of effect and implications for practice. British Journal of Ophthalmology 88(12): 1552-1556.

5. Kalikivayi V, NaduvilathT, AK Bansal, L Dandona (1997) Visual impairment in school children in southern India. Indian Journal of Ophthalmology 45(2): 129-134.

6. Singh H, Saini V, Yadav A, Soni B (2013) Refractive Errors in School Going Children - Data from a School Screening Survey Programme. National Journal Community Medicine 4(1): 137-140.

7. Webber A, Wood J (2005) Amblyopia: prevalence, natural history, functional effects and treatment. Clinical and Experimental Optometry 88(6): 365-375.

8. Amorim G, Oréfice F, Nobre GFD, Dilene de Brito Souza, Rocha MLR, et al. (2005) Prevalence of refractive errors in students in North-eastern Brazil. São Paulo: Arquivos Brasileiros de Oftalmologia 68(3).

9. Cornet V, Auzemery, S., Momo G (2001) Prévalence des troubles de la réfraction chez les enfants scolarisés en premier cycle à Bamako. Mali: IOTA.
10. Gilbert C, Rahi J, Quinn G (2003) Visual impairment and blindness in children. In J Minassian W West (Eds) Epidemiology of eye disease. UK: Arnold Publishers.

11. Kim IS, Kim HB, Lee JW, Kwack YS, Chung SJ, et al. (1971) Refraction in high school students. Journal of Korean Ophthalmology Society 12(2): 67-72.

12. Matta S, Matta P, Gupta V, Dev A (2006) Refractive errors among adolescents attending ophthalmology. Indian Journal of Community Medicine 31(2): 114.

13. Nwosu SN, Alozie IU (2006) Refractive errors in school children in Onitsha. Nigerian Journal of Health and Biomedical Science 5(1): 114117.

14. (2014) Programme National de Lutte contre la Cécité. Appréciation Rapide de la Cécité Evitable. Lomé: PNLC.

15. Sethi S, Kartha G (2000) Prevalence of refractive errors in school children (12-17 years) of Ahmedabad City. Indian Journal of Community Medicine 25(4): 181-183.

16. Thompson J, Woodruff G, Hiscox F, Strong N, Minshull C (1991) The incidence and prevalence of amblyopia detected in childhood. Public Health 105(6): 455-462.

17. (2014) Release of the new global estimates on blindness and visual impairment. World Health Organization.

18. (1997) Global initiative for the elimination of avoidable blindness. World Health Organization Geneva: WHO. 